\title{
The contributions of combustion of different hard steam coal size grades to overall potential mercury emission in Poland
}

\author{
Ireneusz Pyka ${ }^{1, a}$, and Krzysztof Wierzchowski ${ }^{1}$ \\ ${ }^{1}$ Glowny Instytut Gornictwa, Plac Gwarkow 1, 40-166 Katowice, Poland
}

\begin{abstract}
Different groups of hard coal consumers use various coal size fractions. Therefore, knowing the content of mercury in different coal size fraction one can predict the potential contribution of various coal users to the overall mercury emission in Poland. The article emphasized the potential contribution of mercury emission from residential coal burning to the overall mercury emission in Poland. The base for the discussion is the results of research on mercury content in Polish commercial coal products. All hard steam coal sizes (coal classes) were under consideration. The results confirmed that under Polish conditions the contribution of the residential coal burning is smaller than presented in different papers and inventories concerning global mercury emissions.
\end{abstract}

\section{Introduction}

Anthropogenic emissions of mercury create global threats. They result from the both toxicity of compounds of mercury as well as from mobility of mercury in the environment and the lack of natural ways of mercury degradation. Different statistics, inventories and studies have emphasised a huge share of mercury emissions from the residential use of coal in the total anthropogenic mercury emissions for many years. It was estimated that around $43-44 \%$ of coal combustion leads to mercury emissions $[1,2,3]$. The latest publications undermine the previous approach. According to the UNEP publication [4], emission of mercury from coal general use of coal, including residential, is a minor share on the global scale but there no data were presented.

Pacyna et al. [3] gives the values of emission factors used for the assessment of mercury emission in 2005. For the residential coal use this factor is $300 \mu \mathrm{g} / \mathrm{kg}$ of coal used. This value can be regarded as relatively high but under Polish conditions one can find the justification for it. In the WHO IAQ Guidelines [5] one can find the values of mercury content in hard coals used in Poland in the residential sector. The range from $140-1780 \mu \mathrm{g} / \mathrm{kg}$ is attributed to such fuels.

All above confirm the need to recognize the real scale of content of mercury in Polish hard coal and the real mass (load) of mercury in the used coal. It will allow assessment of the real environmental risks as well as preventive measures to implement.

The residential sector in Poland is consuming annually 9-11 Mg of hard coal for the last few years. The sector shares around $13 \%$ of the total coal use in Poland. Coal secures around $29 \%$ of energy needs of residential sector in Poland [6]. It is the highest level among the EU countries (Table 1).

\footnotetext{
${ }^{\text {a }}$ Corresponding author: i.pyka@gig.eu
} 
Table 1. Share of hard coal use in the final energy usage in residential sector in some EU - members (with significant coal use in the residential sector) [6].

\begin{tabular}{|c|c|}
\hline Country & Coal use share, $\%$ \\
\hline EU-27 & 3 \\
\hline Bulgaria & 7 \\
\hline Ireland & 7 \\
\hline Lithuania & 3 \\
\hline Latvia & 2 \\
\hline Poland & 29 \\
\hline Hungary & 2 \\
\hline
\end{tabular}

For European Union member countries, excluding Poland, the share of coal in the final energy use in the residential sector is very small. For Poland alone, with the share of the residential sector in the coal domestic use amounting $13 \%$, the share of this sector in overall mercury emission cannot be like in above mentioned documents [1, 2, 3].

The article presents the assessment of contributions of the combustion of different hard steam coal size classes to the overall mercury emission in Poland. Four groups of hard steam coal size classes are under consideration:

- coarse coal (e.g.: cobbles, coal nuts) - size fraction $+25 \mathrm{~mm}$,

- medium coal (pea coals) - size fraction $8-31.5 \mathrm{~mm}$,

- small size fraction $-20(31.5 / 6) \mathrm{mm}$

- fine coal - about $-1 \mathrm{~mm}$.

Applying rough assumption that the coarse and medium coal classes as well as the finest coals are mainly used in the residential sector and smalls are used mainly in professional and industrial power plants, one can assess the contribution of combustion of hard steam coal split into such two groups of coal users to coal combustion resulting mercury emission in Poland.

\section{Materials and methods}

In 2014 all coal size grades produced in Polish collieries producing hard steam coal (excluding collieries belonging to Jastrzebska Spolka Weglowa S.A.) were sampled and data on their annual production were collected. It served to assess the weighed mean vales of mercury content in groups of coal size groups as well to assess the mass (load) of mercury "carried" by all coal size groups under consideration.

Gross samples of all coal sizes were collected in portions taken for one to two weeks, depending on local conditions. It was collected at the same time in routine sampling operations in all collieries under consideration. Sampling has conformed to requirements of the following standards:

- Hard coal and brown coal. Methods of sampling and laboratory samples preparation PN90/G-04502

- Hard coal and coke - Mechanical sampling - Part 2: Coal - Sampling from moving streams PN-ISO 13909-2

- Hard coal and coke - Mechanical sampling - Part 3: Coal - Sampling from stationary lots PN-ISO 13909-3

- Hard coal and coke - Mechanical sampling - Part 4: Coal - Preparation of test samples PNISO 13909-4

- Hard coal and coke - Manual sampling PN-ISO 18283. 
Mercury content was determined using the certified internal procedure, elaborated in Glowny Instytut Gornictwa No. SC-1.PB.23 applying the Cold-Vapor Atomic Absorption Spectrometry, using analyzer MA-2000 of Nippon Instrument Corporation. It is fully automated measurement system for determination of mercury content in solid materials, gases and liquids through sample combustion or evaporation.

The results of determinations of mercury content in coal in this article are given in $\mu \mathrm{g} / \mathrm{kg}$.

\section{Results and discussion}

A number of 183 samples of hard steam coal size grades were taken from 31 collieries in 2014. It was split into:

- 44 samples of coarse coal size with weighted mean mercury content: $64 \mu \mathrm{g} / \mathrm{kg}$,

- 31 samples of medium coal size with weighted mean mercury content: $87 \mu \mathrm{g} / \mathrm{kg}$,

- 78 samples of small coal with weighted mean mercury content: $81 \mu \mathrm{g} / \mathrm{kg}$,

- 30 samples the finest coal with weight mean mercury content: $113 \mu \mathrm{g} / \mathrm{kg}$.

The weighted mean mercury contents in Polish hard steam coal, for analysed coal size groups were relatively small and in the case of the coarse and medium size were very small. The latest could be explained by the fact that these are cleaned coal only. The average mercury content in hard coal in the global scale was assessed to be ca. $100 \mu \mathrm{g} / \mathrm{kg}$ [7]. Even if we assume that the whole mercury content will be emitted to the atmosphere during combustion process, the values of $64,87 \mu \mathrm{g} / \mathrm{kg}$, as well as 81 and $113 \mu \mathrm{g} / \mathrm{kg}$ are far much smaller than the value equal to $300 \mu \mathrm{g} / \mathrm{kg}$.

Using the values of annual production of sampled hard steam coal size groups, the annual load (mass) of mercury for size classes under consideration were calculated. It was done for the production of each colliery separately. The results are shown in Figure 1.

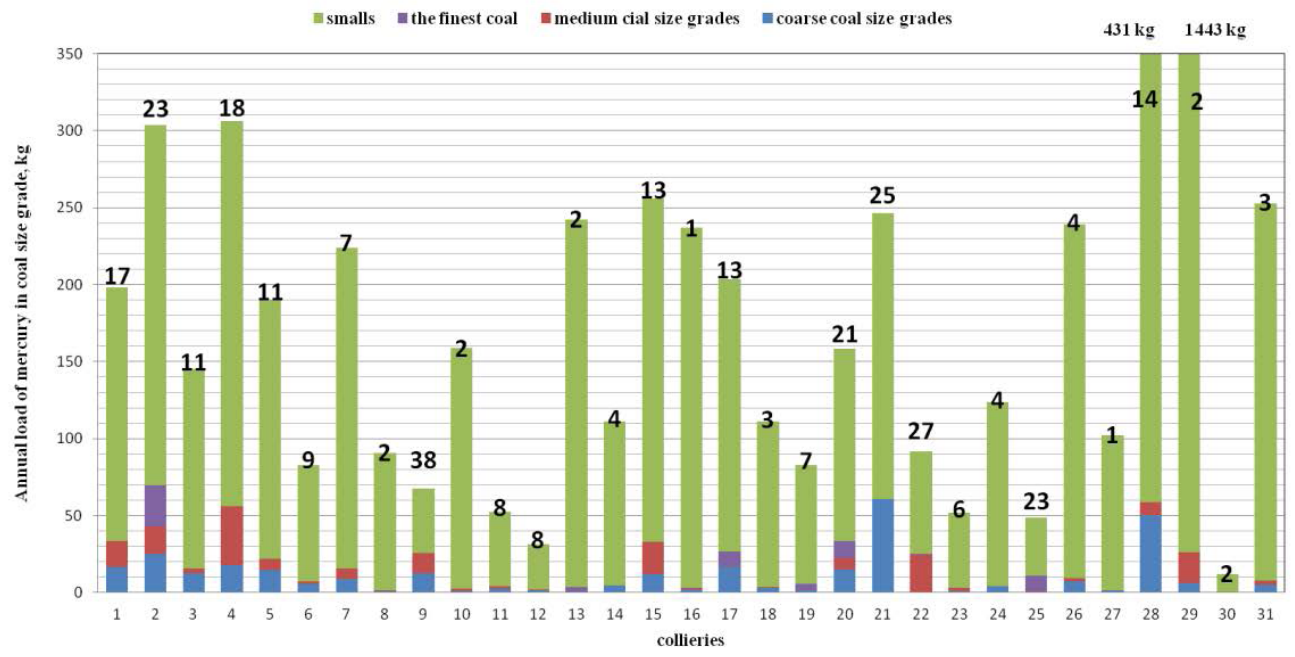

Figure 1. Annual load (mass) of mercury in coal size groups for hard steam coal produced in 31 Polish collieries in 2014.

The numbers in Figure 1 are the values of the share of mercury load in coarse, medium coal size groups and the finest coal being the basic fuel for the residential sector, in total load of mercury in hard steam coal produced in a given colliery. The mean value of this share for the total hard steam coal production in Poland in 2014 was $9 \%$. 
The load of mercury in hard steam coal sampled in 31 collieries in 2014 was around $6296 \mathrm{~kg}$ and it split into:

- coarse coal: $315 \mathrm{~kg}$,

- medium coal: $198 \mathrm{~kg}$,

- smalls: $5717 \mathrm{~kg}$,

- the finest coal: $66 \mathrm{~kg}$.

Only in the case of one colliery (number 9 in Figure 1) the share of mercury load in coarse, medium coal size groups and the finest coal in total load of mercury in hard steam coal produced in given colliery was high and equal to $38 \%$. For the rest of collieries this share was much smaller and in some case it was equal only to $2 \%$. The mean value as $9 \%$ showed that that was no reason, discussing the load of mercury in coal fuel dedicated to the different coal consumers, to foresee that emission of mercury from the residential sector can be comparable with the professional and industrial power plants.

The load of mercury does not mean its emission from coal combustion. It is well known that the mercury emission reduction does not require application of mercury dedicated method. As an accompanying effect, the reduction of mercury emissions occurs in other emissions reduction processes, of ash, $\mathrm{SO}_{\mathrm{x}}$ and $\mathrm{NO}_{\mathrm{x}}$. There are many papers dealing with this topic and the effect of this reduction depends on many parameters, including coal properties $[7,8,9]$. The value $80 \%$ was taken for further analyses, although such high reduction occurs not in all professional and industrial power plants.

There are not so many works done to assess reduction of mercury emission from small boilers in the residential sector. However, even no environmental protection installations are used there, it is estimated that such reduction occurs and is assessed to be $50 \%$ [10].

Using values of mercury load in basic fuels for the residential sector as well as professional and industrial power plants and the above mentioned values of potential mercury emissions reduction, one obtains the possible values of mercury emissions for both sectors: $1143 \mathrm{~kg}$ of mercury emitted from professional and industrial power plants and $289 \mathrm{~kg}$ of mercury emitted from the residential sector in Poland. The first one is almost 4 times greater than the second. So, in the case of Poland, the country where the share of coal in the final energy usage in the residential sector is the highest among EU member countries, the relation between the emissions from both analyzed groups of coal consumers are far from internationally presented data $[1,2,3]$.

\section{Conclusions}

1. Mercury emission has become the topic of international discussions as well as regulatory works. In many papers a great deal of uncertainty related to the data on mercury emission is emphasized. To await good results of regulatory works, the knowledge on mercury content in coal and mercury emission from coal combustion should be based on direct measurement results but not factors adopted from research results done in single location.

2. Hard steam coal use is not limited to electricity and heat generation in professional and industrial power plants. Coal is also used in the residential sector and combusted in small boilers without installations reducing the impact of such combustion on the environment (mainly the atmosphere). For Poland, where the use of coal in residential sector is significant, it was demonstrated that any inventories on the share of this sector in the global mercury emissions may be overestimated.

3. although hard coal is not the best fuel for the residential sector in Poland, the majority of coal combusted locally is a good quality fuel with low mercury content equal to less than $100 \mu \mathrm{g} / \mathrm{kg}$.

4. The load of mercury in the coal fuel used in the residential sector was estimated to be around 580 $\mathrm{kg}$ per year. It is only $9 \%$ of the mercury load in hard steam coal produced annually in Poland. Due to the significant reduction of mercury emissions in the professional and industrial power plants, even no direct methods are applied, the comparison of emission of mercury from the residential sector, professional and industrial power plants will give different result than the comparison of 
mercury loads. However, the mercury emission reduction occurs in residential sector and it is difficult to say that the mercury emissions in both sectors are comparable.

\section{Acknowledgements}

The results of determination of mercury commercial products (coal size classes) of the Polish hard coal collieries have been obtained from the project founded within the framework of the Applied Research Program of the Polish National Centre for Research and Development entitled The elaboration of a data base on mercury content in domestic coal, technological guidelines of further mercury reduction, including the defining of benchmarks for domestic indices of mercury emissionacronym "Hg Base" ("Baza Hg"), (PBS2/A2/14/2013).

\section{References}

1. UNEP-United Nations Environmental Programme. Process Optimization Guidance for Reducing Mercury Emissions from Coal Combustion in Power Plants, (Division of Technology, Industry and Economics (DTIE) Chemicals Branch, Geneva, Switzerland, 2010)

2. UNEP Chemical Branch. The Global Atmospheric Mercury Assessment: Sources, Emissions and Transport, (UNEP-Chemicals, Geneva, 2008)

3. E.G. Pacyna, J.M.Pacyna, K.Sundseth, J.Munthe, K.Kindbom, S.Wilson, F.Steenhuisen, P.Maxson, Atmos. Environ., 44, 2487 (2010)

4. UNEP-United Nations Environmental Programme. Global Mercury Assessment 2013: Sources, Emissions, Released Environmental Transport, (UNEP Chemicals Branch, Geneva, Switzerland, 2013)

5. WHO IAQ Guidelines. Household fuel combustion (2014).

6. Central Statistical Office. Energy consumption in households. Statistical Information and elaborations (Warsaw, 2014)

7. UNEP Expert Group on BAT/BEP, http://www.mercuryconvention.org/Negotiations/BATBEP ExpertGroup/CommentsonBATBEPguidance/tabid/4545/Default.aspx (2015)

8. J.H. Pavlish, E.A. Sondreal, M.D. Mann, E.S. Olson, K.C. Galbreath, D.L. Laudal, S.A. Benson, Fuel Process. Technol., 82, 89 (2003).

9. L.L. Sloss, Legislation, standards and methods for mercury emissions control, CCC/195 (London, IEA Clean Coal Centre, 2012)

10. S. Hlawiczka, K. Kubica, U. Zielonka, Sci. Total Environ., 312, 261 (2003) 